\title{
The Value of Songs for Teaching and Learning Cardiopulmonary Resuscitation (CPR) Competencies: A Systematic Review
}

\author{
Jeffrey L. Pellegrino ${ }^{1}$, Jennifer Vance ${ }^{2}$, Nicholas Asselin ${ }^{3}$ \\ 1. School of Disaster Sciences and Emergency Services, University of Akron, Akron, USA 2. Nursing, Aultman College of \\ Nursing and Health Sciences, Canton, USA 3. Emergency Medicine, Brown University, Providence, USA
}

Corresponding author: Jeffrey L. Pellegrino, jpellegrino@uakron.edu

\begin{abstract}
We sought to summarize, in a systematic review, the effectiveness of songs to support learning, performance, and recall of quality characteristics of cardiopulmonary resuscitation (CPR) compression rate, and depth. We systematically reviewed the literature from eight academic indexes from the fields of medicine, nursing, allied health, and education, from 2014 to 2020 to identify studies that evaluated an intervention of song use during CPR training against control and reported outcomes of compression rate and depth.
\end{abstract}

There were 185 studies initially identified for review, eight met criteria for inclusion and analysis. For the critical outcome of compression depth, a pooled song group $(\mathrm{n}=446)$ when compared to a non-song group $(n=443)$ demonstrated higher odds of being in the recommended range (OR 3.47). All studies, however, performed an average compression depth shallower than recommended guidelines in each arm. The available literature, we found, utilized heterogenous methodology and was at high risk of bias. When pooled, there were trends towards improved CPR metric performance in groups who were exposed to songs during treatment, though this only reached significance when groups were tested at $>30$ days from initial exposure. Findings of lower compression rates in the song groups suggest that song selection should favor beats per minute closer to the midpoint of the 100-120 ideal range to allow for variation when used as mental metronomes.

Received 02/04/2021 Review began 04/14/2021 Review ended 05/12/2021 Published 05/16/2021

○ Copyright 2021 Pellegrino et al. This is an open access article distributed under the terms of the Creative Commons Attribution License CC-BY 4.0, which permits unrestricted use, distribution, and reproduction in any medium, provided the original author and source are credited.

Categories: Emergency Medicine, Medical Education, Public Health

Keywords: teaching aids, learning, bpm, first aid, education, cpr, resuscitation, songs, mental metronome, compression

\section{Introduction And Background}

The benefits of early and proper cardiopulmonary resuscitation (CPR) for a person in sudden cardiac arrest prior to Emergency Medical Services (EMS) arrival improve the odds of survival to release from a hospital two to three-fold from those not receiving lay responder CPR [1]. As health practitioners, we are in the position to not only provide quality evidence-based CPR but prepare and or educate individuals and the public to respond alike. However, the public does not have the same motivation, access to continued training, or legal mandate to be proficient in basic life support (BLS) skills of CPR. Response by laypersons (not-medically trained) is a complicated set of competencies that involves knowledge, skills, and behaviors specific to cardiac arrest, wrapped in a set of the attitude of willingness, self-efficacy, and confidence in one's ability to save a life [1-6]. Thus far, efforts to improve lay response in cardiac arrest have included mass training events [7], training "prescriptions" for high-risk groups [8], technology-driven solutions to alert trained responders to emergencies [9], and the development of telecommunicator CPR for just in time training [10]. These efforts assume that there is a basic pedagogy for effective CPR.

The International Liaison Committee on Resuscitation provides a consensus on science and treatment recommendations that the American Heart Association and American Red Cross use to identify the components of effective chest compressions and their significance to survival [11,12]. Effectiveness was a combination of correct hand position, compression rate, compression depth, and chest wall recoil. Making these CPR competencies accessible to BLS learners in training ideally translates to competent actions in emergency situations, which motivated us to identify evidence of effective and efficient educational tools to use across training modalities.

A perennial question from the field, both the public and instructors, to the American Red Cross' national Scientific Advisory Council, concerns the efficacy of using music to teach or associate the current 100-120 chest compressions per minute (CPM) rate. Public health messaging, training programs, and individual educators have been promoting or using songs like "Stayin' Alive" [13] to provide a cadence for learning and inspiring recall for the rate of compressions. Traditionally, facilitated/coached practices supplement audio/video-guided demonstrations to provide guidance and feedback during the practice of compressions [14-22]. Teaching initial compression competencies as well as supporting recall challenges CPR educators to 
understand the physical, social, and technological backgrounds of learners. The longitudinal recall is important because of the potentially long duration before an emergency might require action. Compressiononly CPR is now taught to simplify and reduce barriers to the action of lay responders, which makes teaching compressions effectively a priority $[23,24]$. Songs, as a classroom tool, are an extension of metronome type guidance in a relatively inexpensive and potentially socially connected manner. They may also be supportive of recall and mentally guide compressions when technology is not available to provide active or passive feedback (e.g., automated external defibrillator [AED] prompts, smartphone apps, or telecommunicators).

Opportunities to engage music as a device for initially learning the CPR compression rate, assist in recall of the rate, and pace actual compressions may offer training organizations and individual educators new tools to engage learners and meet their educational and health outcomes. The value of songs in this education process is the subject of this systematic review of existing literature. The research question for this review: do songs (or does music) improve the learning and/or performance of CPR compressions?

\section{Review}

This review was approved by the Scientific Advisory Council of the American Red Cross as an update to an internal 2014 review of this question.

\section{Eligibility and inclusion criteria}

The participants in studies were individuals learning or demonstrating CPR chest compression competencies, there was no exclusion by age. Each study needed to have an educational intervention that included a song to teach, coach, or assist with a recall of CPR compression rate. Studies also needed a comparison or control group. We looked to identify the critical outcomes of compression rate and compression depth at zero days post-training, 1-29 days, and $>30$ days post-training. Important outcomes included chest compression rate, depth, fraction, learner self-efficacy, and learner confidence. We excluded studies that were not published original research articles on randomized and non-randomized education interventional studies or observational studies with a comparator group. Although we were most interested in lay responder outcomes, we did not exclude health professionals because outcomes could be potentially extrapolated. Publication dates were between 2014 and 2020, due to a previous review of the literature by the Red Cross from 2010 to 2014. Abstracts needed to be in English for initial inclusion.

\section{Information sources}

The following electronic databases were searched due to their coverage of health, education, and psychometric topics: PubMed, Embase, CINAHL, ERIC, Psychology and Behavioral Sciences Collection, PsycARTICLES, Health Source: Nursing/Academic Edition/Health Source: Consumer Edition, and The Networked Digital Library of Theses and Dissertations (NDLTD). See Appendix A for search strategy strings, developed with the Health Science Library of the New York Medical College. We searched reference lists from included studies and reviewed articles for additional papers.

\section{Study Selection}

We used predefined criteria for what citations to include, which Author A and Author B independently applied for initial screening, utilizing Rayyan QCRI web software [25]. Titles and abstracts with clearly unrelated content were "excluded" from further analysis. Citations marked as "include" or "maybe" by either of the reviewers were included in the next level of review. Disagreements at the full article stage were resolved through consensus with the assistance of a third reviewer (Author C). A record was kept of all studies excluded at the full-text stage, along with the reason.

Data Collection Process

Author B extracted the intervention characteristics and data of interest by hand from the studies and Author A checked the extracted data, and any discrepancies were resolved through consensus utilizing Review Manager (RevMan) 5.3. 


\section{Cureus}

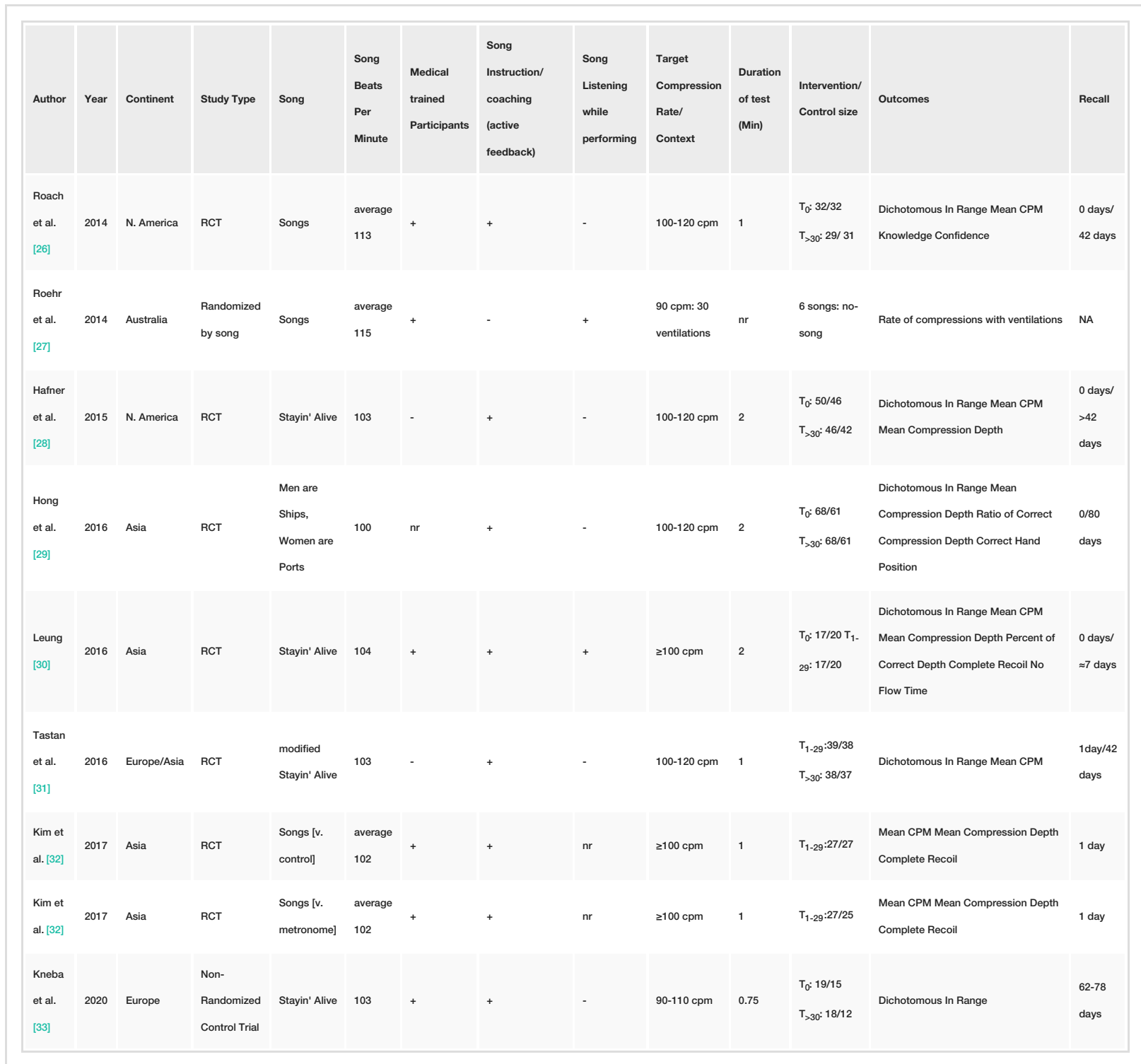

\section{TABLE 1: Characteristics of Included Studies}

The same study, comparator though is to metronome guidance v. no song

$\mathrm{NA}=$ Not Applicable; $\mathrm{nr}=$ not reported; $\mathrm{cpm}$ = compressions per minute; RCT = Randomized Control Study

Characteristics that were cataloged included: continent of origin, study type, song title and beats per minute (BPM), population description (medically trained; Children), population, and sample size. We also identified if the integration of song was for instruction/coaching (active feedback) purposes or listening while performing (recall). Finally, we cataloged the target rate of intervention, duration of the test (Min), intervention/ control size, outcomes, and recall time periods (see Table 1).

Data items of interest included: percentage at adequate rate, variability of CPM, percentage with adequate depth, and variability compression depth.

\section{Results}

Study Selection

Comprehensively, the search identified 125 unique citations (from results in PubMed-55; Embase-91; CINHAL-34; ERIC 1; Psychology and Behavioral Sciences Collection-1; Health Source: Nursing/Academic Edition / Health Source: Consumer Edition-2; and The Networked Digital Library of Theses and Dissertations (NDLTD)-2). Overall, eight studies were included for review. Common reasons for exclusion were the lack of a comparator or incomplete data from conference abstracts. For abstract only publications originally identified, we attempted contact with corresponding authors but received no additional 


\section{Cureus}

information (see Figure 1).

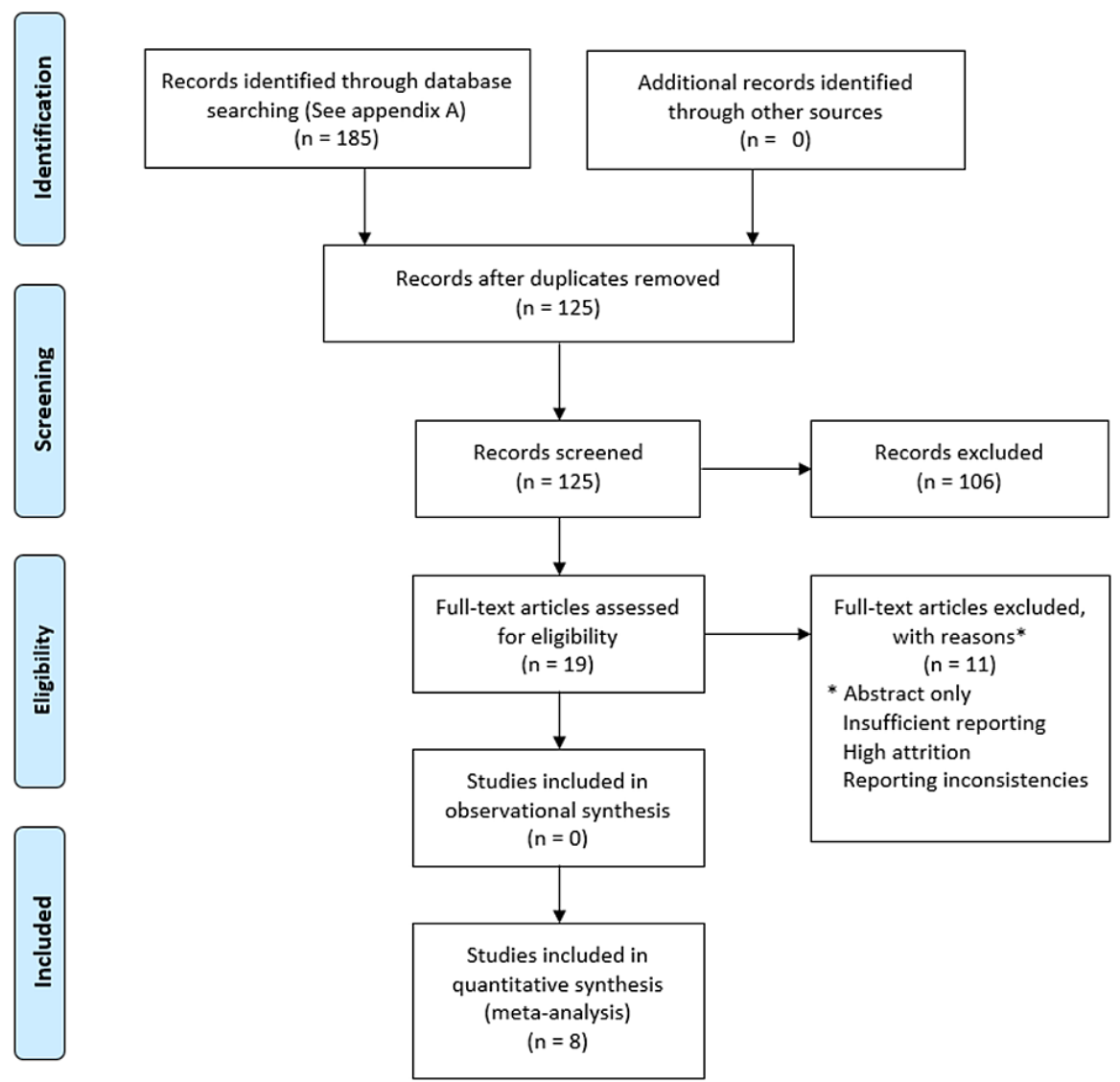

\section{FIGURE 1: PRISMA Reporting}

From: Moher D, Liberati A, Tetzlaff J, Altman DG, The PRISMA Group (2009). Preferred Reporting Items for Systematic Reviews and Meta-Analyses: The PRISMA Statement. PLoS Med 6(6): e1000097. doi:10.1371/journal.pmed1000097

Study Characteristics

The studies originated from multiple continents, including Asia (3), Australia (1), Europe (1), Europe/Asia (1), and N. America (2). Six included medically trained participants and none reported enrolling children. Six utilized songs in instruction and/ or coaching of compressions. Only two utilized songs while performing compressions in assessments. No studies reported any patient outcomes. We summarized the type of settings, populations, and study designs for each group (see Table 1).

The report of outcomes varied between the studies regarding measuring CPM. Some reported mean and standard deviations, while others reported a percentage of those in the target range. Mean compression depth was also identified for meta-analysis. We grouped the studies by times of assessment postintervention with $\mathrm{T}_{0}$ representing immediately post-intervention, and then $\mathrm{T}_{1{ }^{-} 29}$ or $\mathrm{T}_{>30}$ representing days post-intervention. Studies did present secondary outcomes but not in a manner for meta-analysis. The data are reported in individual study descriptions.

\section{Critical Appraisal Within Studies}

Author B evaluated each included study for risk of bias, as recommended by the Preferred Reporting Items for Systematic Reviews and Meta-Analyses Extension for Scoping Reviews (PRISMA-ScR) Checklist [34]. Evaluation within the studies demonstrates a high-risk bias in terms of design and methodology (see Figures 2, 3). 


\section{Cureus}

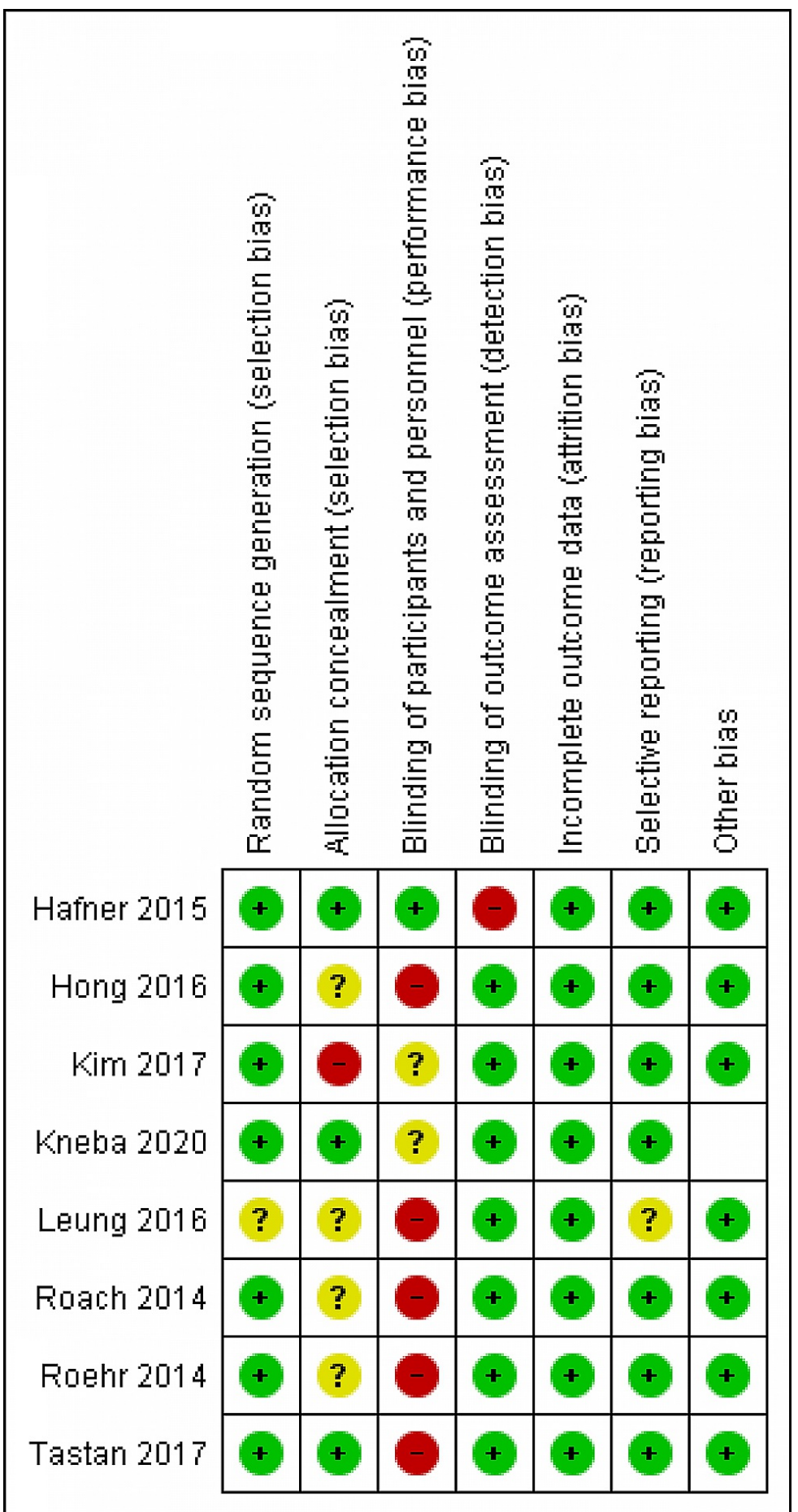

FIGURE 2: Risk of bias summary: review authors' judgments about each risk of bias item for each included study. 


\section{Cureus}

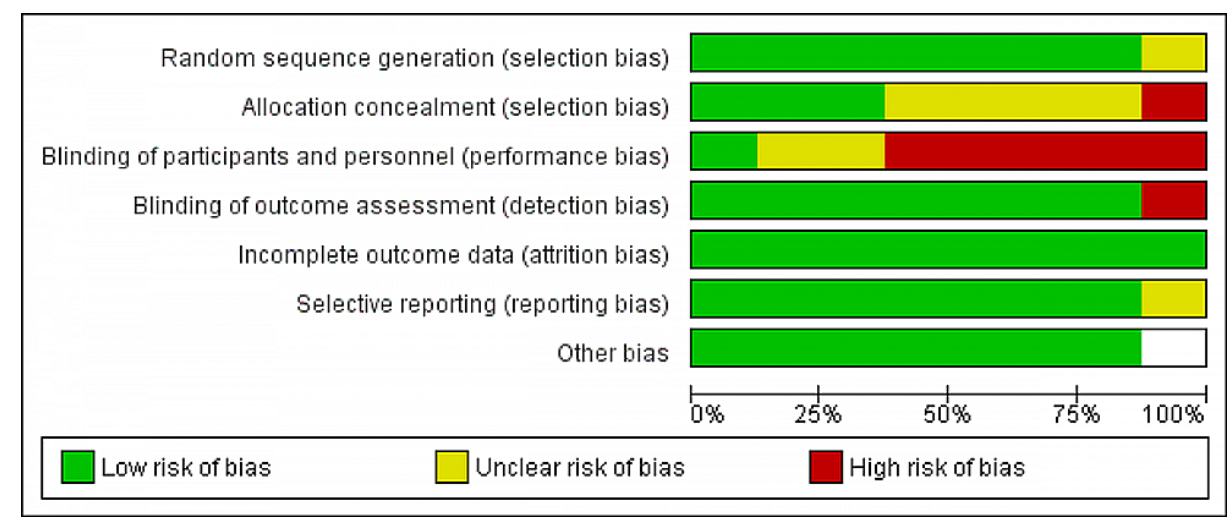

FIGURE 3: Risk of bias graph: review authors' judgments about each risk of bias item presented as percentage

Roach et al. worked with a group of nurses who did not perform at the recommended compression rate on a pre-test [26], nurses were randomized and retrained with the aid of coaching, demonstration, and the use of one of six songs chosen by the participant, compared to another group receiving similar retraining but without a song. It was noted that groups differed in variability ranging from 30-180 cpm in the no-song group compared to $80-150 \mathrm{cpm}$ in the song group. At $\mathrm{T}_{0}$, there was a difference in favor of the song group averaging within the recommended rate, while the non-song group was just below rate, but significantly different in a ratio within the recommended range. At $\mathrm{T}_{>30}$ no difference was seen between groups and both performed within the recommended range or mean rate (see Tables 2, 3). Knowledge and confidence measures were not independent by the intervention group. 


\section{Cureus}

\begin{tabular}{|c|c|c|c|c|c|c|c|c|c|}
\hline \multirow[b]{2}{*}{ Name } & \multicolumn{2}{|c|}{ Song Group } & \multicolumn{2}{|c|}{ Comparison Group } & \multirow[b]{2}{*}{ Effect Estimate } & \multirow[b]{2}{*}{ SE } & \multirow[b]{2}{*}{ Cl Start } & \multirow[b]{2}{*}{ Cl End } & \multirow[b]{2}{*}{ Weight } \\
\hline & Within Range & Total 1 & Within Range & Total 2 & & & & & \\
\hline \multicolumn{10}{|l|}{$\mathrm{T}_{0}$} \\
\hline Leung [30] & 13 & 17 & 17 & 20 & 0.6 & 0.8 & 0.1 & 3.0 & 6.0 \\
\hline Hafner et. al. [28] & 24 & 50 & 18 & 46 & 1.4 & 0.4 & 0.6 & 3.2 & 10.3 \\
\hline Roach et al. [26] & 21 & 32 & 13 & 32 & 2.8 & 0.5 & 1.0 & 7.7 & 9.2 \\
\hline Hong et al. [29] & 65 & 68 & 53 & 61 & 3.3 & 0.7 & 0.8 & 12.9 & 7.3 \\
\hline Kneba et al. [33] & 15 & 19 & 1 & 15 & 52.5 & 1.2 & 5.2 & 528.5 & 4.0 \\
\hline \multicolumn{10}{|l|}{$\mathrm{T}_{1-29}$} \\
\hline Kim et al. [32] & 18 & 27 & 16 & 27 & 1.4 & 0.6 & 0.5 & 4.2 & 8.6 \\
\hline Leung [30] & 15 & 17 & 16 & 20 & 1.9 & 0.9 & 0.3 & 11.8 & 5.4 \\
\hline I astanet al. [31] & 34 & 39 & 16 & 38 & 9.4 & 0.6 & 3.0 & 29.2 & 8.5 \\
\hline $\mathrm{T}_{>30}$ & 155 & 198 & 82 & 184 & 4.9 & & 2.2 & 10.9 & 40.8 \\
\hline Roach et al. [26] & 18 & 29 & 15 & 31 & 1.7 & 0.5 & 0.6 & 4.9 & 9.1 \\
\hline Hafner et al. [28] & 34 & 46 & 18 & 42 & 3.8 & 0.5 & 1.5 & 9.3 & 9.8 \\
\hline Tastan et al. [31] & 32 & 37 & 23 & 38 & 4.2 & 0.6 & 1.3 & 13.1 & 8.4 \\
\hline Kneba et al. [33] & 9 & 18 & 1 & 12 & 11.0 & 1.1 & 1.2 & 103.9 & 4.1 \\
\hline Hong et al. [29] & 62 & 68 & 25 & 61 & 14.9 & 0.5 & 5.6 & 39.7 & 9.3 \\
\hline
\end{tabular}

TABLE 2: Dichotomous outcomes of song group compared to other or no-song group within expected compression rate range

Analysis computed by Review Manager (RevMan) [Computer program]. Version 5.3. Copenhagen: The Nordic Cochrane Centre, The Cochrane Collaboration, 2014. 


\section{Cureus}

\begin{tabular}{|c|c|c|c|c|c|c|c|c|c|c|c|}
\hline & \multicolumn{3}{|l|}{ Group } & \multicolumn{3}{|c|}{ Group } & \multirow[b]{2}{*}{ Mean Difference } & \multirow[b]{2}{*}{$\begin{array}{l}\text { Effect } \\
\text { Estimate }\end{array}$} & \multirow[b]{2}{*}{ SE } & \multirow[b]{2}{*}{ Cl Start } & \multirow[b]{2}{*}{ Cl End } \\
\hline & Mean & SD & Total & Mean & SD & Total & & & & & \\
\hline \multicolumn{12}{|l|}{$\mathrm{T}_{0}$} \\
\hline Roach et al. [26] & 106.7 & 9.0 & 32.0 & 99.1 & 9.0 & 32.0 & 7.6 & 2.3 & 3.2 & 12.0 & 15.4 \\
\hline Leung [30] & 111.0 & 10.2 & 17.0 & 111.9 & 9.6 & 20.0 & -0.9 & 3.3 & -7.3 & 5.5 & 7.3 \\
\hline Hafner et al. [28] & 109.0 & 15.0 & 50.0 & 121.0 & 21.0 & 46.0 & -12.0 & 3.8 & -19.4 & -4.6 & 5.5 \\
\hline \multicolumn{12}{|l|}{$\mathrm{T}_{1-29}$} \\
\hline Leung [30] & 107.9 & 5.0 & 17.0 & 108.1 & 8.3 & 20.0 & -0.2 & 2.2 & -4.5 & 4.1 & 15.9 \\
\hline Kim et al. [32] & 98.2 & 9.1 & 27.0 & 98.5 & 16.7 & 25.0 & -0.3 & 3.8 & -7.7 & 7.1 & 5.5 \\
\hline Kim et al. [32] & 98.2 & 9.1 & 27.0 & 110.4 & 15.3 & 27.0 & -12.2 & 3.4 & -18.9 & -5.5 & 6.6 \\
\hline $\begin{array}{l}\text { Tastan et al. } \\
\text { [31] }\end{array}$ & 107.3 & 7.3 & 39.0 & 121.5 & 12.9 & 38.0 & -14.1 & 2.4 & -18.8 & -9.4 & 13.6 \\
\hline \multicolumn{12}{|l|}{$\mathrm{T}_{>30}$} \\
\hline [31] & 106.2 & 8.7 & 37.0 & 100.7 & 9.5 & 38.0 & 5.5 & 2.1 & 1.4 & 9.7 & 17.5 \\
\hline Roach et al. [26] & 103.9 & 14.0 & 29.0 & 100.9 & 12.0 & 31.0 & 3.0 & 3.4 & -3.6 & 9.6 & 6.8 \\
\hline Hatner et al. [28] & 111.0 & 13.0 & 46.0 & 120.0 & 20.0 & 42.0 & -9.0 & 3.6 & -16.1 & -1.9 & 5.9 \\
\hline
\end{tabular}

\section{TABLE 3: Mean compression rate outcomes of song group compared to other or no-song group}

Analysis computed by Review Manager (RevMan) [Computer program]. Version 5.3. Copenhagen: The Nordic Cochrane Centre, The Cochrane Collaboration, 2014.

Roehr et al. [27] compared six simulations of infant resuscitation each with a different song (randomized from a group of five) and no-song (baseline). Thirty medical professionals participated in the study, working in teams of two, alternating compressions and inflation by song. Of the five songs, only Abba's song "SOS," [35] was significantly different than the baseline and closer to the intended rate, for compressions and ventilations. Two of the comparison songs were also at 120-bpm as SOS but not statistically different from the other comparisons. This study was excluded from the meta-analysis because they included ventilation in its ratio and rate.

Hafner et al. [28] compared adults with no previous CPR training, one group who learned compression rate with the aid of a song at 103-bpm versus a control (no-song) group. The two groups were significantly different with the control group having a faster mean compression rate and a larger standard deviation at $\mathrm{T}_{0}$, 121 (SD 21) compared to 109 (SD 15). The odds ratio had a positive association toward the song group, but not significant. At $\mathrm{T}_{>30}$, the song group was closer to the target and the standard deviations remained wider in the no-song group. The odds ratio significantly favored songs for being in the recommended range. (See Tables 2-3.)

Hong et al. [29] compared adults without current CPR training, one group learned compression rate with the aid of a popular song in Korea versus a control group (metronome guided). Although there were no reported significant differences in the proportions with correct compression rate range, it was noted the popular song group performed at a significantly faster rate than the control group (107.4 cpm v. $102.2 \mathrm{cpm})$ at $\mathrm{T}_{0}$.

However, at follow-up, the metronome group was significantly faster and on average faster than the 
recommended rate $(124.8 \mathrm{cpm}$ v. $110.0 \mathrm{cpm})$. This was reflected by a significant difference between the proportion of those in the recommended range for the popular song group (see Tables 2, 3). Hong et al. reported important outcomes of compression depth, the ratio of correct compression depth, and correct hand position were not significant between groups.

Leung [30] compared pediatric nurses retraining in infant CPR between those practicing with a song (103$\mathrm{bpm}$ ) and no-song. There were no significant differences in mean rate or proportion at the recommended rate $(\geqslant 100 \mathrm{cpm})$ at $\mathrm{T}_{0}$. This study used a recall period of approximately one-week post-course; however, they also did a 30-minute practice session prior to this assessment, which was unique to this study. No significant difference in mean or proportion in the recommended rate was reported (see Tables 2, 3).

Tastan [31] compared student nurses initially learning CPR between those who practiced with a song (103$\mathrm{bpm}$ ) that was modified with an extra rhythm instrument - the traditional Turkish dar-buka and no-song. There were significant differences in mean rate one day after training, with the control group averaging $121.5 \mathrm{cpm}$ compared to $107.3 \mathrm{cpm}$. The proportion in the recommended range also favored the song group. Six weeks post-training, the groups were more similar and both on average within the recommended range. However, the average and proportion of those in the recommended range were significantly different and supportive of the intervention (see Tables 2, 3).

Kim [32] compared third-year medical students compression rates between those who practiced with one of five songs (average bpm 102) from a pre-determined list to allow for familiarity, practiced with a metronome, or no-song. The assessment occurred 24 hours after practice. The mean compression rates were significantly different between the no-song and song group, with the song group just below the recommended rate $(98.2$ $\mathrm{cpm})$ and the no-song in the recommended rate $(110.4 \mathrm{cpm})$. The mean difference was not significantly different between the song and metronome groups, and both were below the recommend $\geqslant 100 \mathrm{cpm}$ (see Tables 2, 3).

Kneba and Humm [33] compared students in a veterinary graduate program on compression rate on canine models between those who practiced with a song (103-bpm) or no-song. The mean compression rates were calculated but did not have standard deviations reported, which prevented meta-analysis. Only one participant of 15 in the no-song group achieved the 90-110 cpm expectation compared to 15 of 19 in the song group, a significant difference at $\mathrm{T}_{0}$. Similarly, at $\mathrm{T}_{>30}$ only one person in the no-song group compared to 8 of 18 in the song group were in the expected range. The average compression rate for the no-song group at both assessments exceeded the $110 \mathrm{cpm}$ expectation (see Table 1).

Summary Findings

We utilized the GRADEpro Guideline Development Tool [Software] [36] and Review Manger 5.3 [37] to systematically analyze similar outcomes. For the critical outcome of compression rate, a meta-analysis of 446 song-group participants compared to 443 no-song group participants yielded an odds ratio (OR) of 3.47 (confidence interval [CI] 2.00, 6.03) favouring the song group (see Appendix B). At specific time categories, odds ratios changed but all favored songs. At $\mathrm{T}_{0}$ the odds ratio favors the use of songs, however, the

confidence interval does not communicate independence from the no-song group (OR 2.60, CI 0.97, 6.97). The mean compression rates were not statistically different (mean difference $1.56, \mathrm{CI}-1.70,4.82$ ). And at $\mathrm{T}_{1-}$ ${ }_{29}$ the odds ratio again favored the use of songs but did not show independence from the non-song group (OR 3.02 , CI $0.81,11.28)$. The mean compression rates were independent, where the song group on average was slower (mean difference -6.68 , CI -9.37, -4.00). Then again at $\mathrm{T}_{>30}$ the odds ratio favored the use of songs and showed independence from the non-song group at $>30$ days (OR 4.92, CI 2.22, 10.94). The mean compression rates were not statistically different (mean difference 2.12 , CI -1.02, 5.27).

For the critical outcome of compression depth, five studies reported mean depth [26,28,30-32]. From a meta-analysis of the combined studies, the mean differences at $\mathrm{T}_{0}, \mathrm{~T}_{1-29}$, and $\mathrm{T}_{>30}$ were not significant or when combined (see Appendix C). With one exception, the mean differences showed a greater propensity and proximity to the guideline recommendation of a minimum of $50 \mathrm{~mm}$ in the non-song group. All studies showed an average depth shallower than the recommendations.

For the important outcomes, chest compression fraction, learner self-efficacy, and learner confidence, there were not consistently used measures between studies. Roach et al. [26] did not identify any significant difference in learner knowledge or confidence in the intervention group. Hong et al. [29] did not identify any significant differences in learner ratio of correct compression depth, or correct hand position. Leung [30] did not identify any significant differences in learner outcomes of complete recoil or no flow times. Kim et al.

[32] did not find any significant difference in complete recoil between song, metronome, or no-song groups.

Summary of Evidence

There is limited evidence to make any standard for the use of a specific song or songs in general because of 
risk of biases and inconsistency of data reporting, however, trends of outcomes provide educators and training organizations direction, from which they may choose to act. For the outcome of greater consistency (aka, smaller standard deviations) the use of songs can contribute to learning outcomes and should be considered a tool for instructors. The choice of song based on BPM has not been established as to where an ideal rate would fall in the given 100-120 range. Notably, for the song group, no average CPM rate was >110, which corresponded with the lower BPM of songs used in the studies. This leaves the need to assess the effect of faster BPM songs on rate and depth to identify value or costs. It is important to emphasize that six of the eight studies were with medically trained participants leaving less direct evidence for the use of songs with the training of lay responders; however, differences in outcomes were not noted.

Depth for all studies was on average shallower for the song groups, which may be the result of attention to rate versus depth or a physiological limitation of rate on depth. There may be some cognitive load on learners, imparted during the studies (bias), particularly in song groups, to emphasize rate. For example, students were encouraged to recall songs during assessments. Future studies may seek to develop an educational emphasis on depth, using songs as a mental metronome to limit cognitive load.

To improve future evidence development and systematic reviews, we encourage that data be reported in dichotomous and continuous formats. Minimum reporting categories for original research moving forward to enhance future comparisons should be established. We recommend that a specific segment of the song used to be analyzed for BPM for consistent and accurate reporting, as there are fluctuations of tempo throughout songs and entire songs are not used. Reporting the role or intention of the song in training (e.g., background beat, synchronization of practice compressions, synchronization during testing) would allow for better comparison and understanding in educational practice. Participant demographics should include if learners were new or previously trained in CPR. Outcomes should be predicated on a stated hypothesis, which was not consistently reported. We also recommend that testing duration be a minimum two minutes to mimic the expectation of five cycles of CPR and when it is more natural to switch compressors. For outcome reporting, average CPM by minute and average compression depth by minute would better describe the role of the intervention in maintaining consistency. Finally, we recommend that authors utilize the Guideline for Reporting Evidence-Based practice Educational interventions and Teaching (GREET) to enhance consistency and validity during the research process.

We believe there is an opportunity for future research to establish the theory and practice of using songs for educational use in CPR. Foundationally, the field must establish that their population/sample can follow a beat, as potentially $14 \%$ of the population may have amusia (aka beat deafness) [38], and be able to compress deep enough at the recommended rate prior to assessing song compliance. Then, future studies on the use of songs must communicate if the song(s) used is already known to or learned by participants versus an unknown/unfamiliar song, as this can impact the length of training and longitudinal recall. Once the previous assumptions are examined, future research between medically trained and lay responders would acknowledge any differences in pedagogy needed within those groups. Additionally, the research could be done between lay responder populations, for example, their use with children. Practically, there is no consensus on what BPM of a song/song segment produces ideal cadence, which needs to be a priority research topic. And, as Tastan et al. [31] brought up, can songs have their beats enhanced to influence results?

An additional area for exploration would be in comparing active compression feedback devices and songs for learning appropriate rate. Active feedback devices offer different interventions to improve compression performance. However future studies can compare outcomes to financial costs of purchasing, maintenance, time on task, etc. of learners and educators between the two tools.

\section{Limitations}

The original question wanted to include outcomes specific to lay responders due to their unique position of initially learning CPR without ongoing support or testing. The body of literature did not allow us to discriminate between lay responders and medically trained responders. Extrapolation between groups may be appropriate as they had similar outcomes in this review, but future research is needed to identify specific characteristics of songs that may prove useful to recalling and performing effective CPR compressions. These future explorations may also include socio-cultural elements of specific songs or style of songs [29], for example, the use of instruments to accent the beat [31]. Similarly, the lack of studies from around the globe may limit the generalization of outcomes based on cultural nuances.

The 20-bpm range difference in lower and upper thresholds of the current recommendations makes comparisons for any clinical differences challenging. The literature does not suggest that 1-bpm over or under is detrimental, nor that compressing at 110 -bpm is better than $100-\mathrm{bpm}$ or 120 -bpm. The Revman5 software had limited ability to deal with reported means when reported within a range versus a single figure. The reports of BPM by song are somewhat problematic as a full song varies in BPM during different sections in some cases. Only one study [29] reported the BPM for the segment used in their study, while others did not differentiate the whole song or segment. 


\section{Cureus}

\section{Conclusions}

From an educational perspective, there is value to the introduction and use of songs for the purpose of narrowing the deviation from recommended ranges and increasing the odds of being within a targeted range during CPR skill education. Longitudinal recall appears to be also favored within groups using songs, which supports the need for additional research as to how, why, and which types of songs would be effective. However, the ideal song is not described in the literature regarding qualities of cultural relevance, distinct cadence, or BPM. We suggest that instructors be able to identify songs that resonate with learners and have a BPM of approximately $110 \mathrm{bpm}$ to better meet recommended compression rate range. More evidence is needed regarding the effect of this on compression depth and recoil as well as the influence of songs on confidence or willingness to perform CPR.

\section{Appendices}

\section{Appendix A: Search Strategy}

PubMed (New Pubmed)

([cpr] OR ["chest compression*"]) OR ("chest wall oscillation"[MeSH Terms] OR "chest wall oscillation"[All Fields]) AND ([music] OR [singing]) OR ([song*] $)$ OR ([metronome* $]$ ) NOT (Song[Author]) Filters: from 2014 to 2020

Search Details:

((((("cardiopulmonary resuscitation"[MeSH Terms] OR ("cardiopulmonary"[All Fields] AND "resuscitation" [All Fields])) OR "cardiopulmonary resuscitation"[All Fields]) OR "cpr"[All Fields]) OR "chest compression*" [All Fields]) OR ("chest wall oscillation"[MeSH Terms] OR "chest wall oscillation"[All Fields])) AND ((((((()("music"[MeSH Terms] OR "music"[All Fields]) OR "music's"[All Fields]) OR "musical"[All Fields]) OR "musicality"[All Fields]) OR "musically"[All Fields]) OR "musicals"[All Fields]) OR "musics"[All Fields]) OR ("singing"[MeSH Terms] OR "singing"[All Fields])) OR "song*"[All Fields]) OR "metronome*"[All Fields])) NOT Song[Author]

55 Results, January 22, 2020 
(/(('resuscitation'/exp OR 'cardiopulmonary resuscitation'/exp OR 'cardio pulmonary resuscitation'/exp OR 'cardiopulmonary resuscitation':ab,ti OR 'cardio pulmonary resuscitation':ab,ti OR cpr:ab,ti OR 'bystander cpr':ab,ti OR 'chest compression':ab,ti OR 'cardiac compression':ab,ti OR 'chest wall compression':ab,ti OR 'thoracic compression':ab,ti OR 'cardiac wall compression':ab,ti OR 'thoracic wall compression':ab,ti OR 'hands-only resuscitation':ab,ti OR 'hands only resuscitation':ab,ti OR 'compression-only cpr':ab,ti OR

\#6 'compression only cpr':ab,ti OR 'heart massage':ab,ti OR 'cardiac massage':ab,ti OR 'thoracic massage':ab,ti OR 'heart arrest/therapy' OR 'cardiac arrest/therapy' OR 'thoracic arrest/therapy') AND ('music'/exp OR music:ab,ti OR song:ab,ti OR songs:ab,ti OR 'singing'/exp OR singing:ab,ti OR humming:ab,ti OR tune:ab,ti OR tunes:ab,ti OR 'melody'/exp OR melody:ab,ti OR melodies:ab,ti OR 'metronome'/exp OR metronome:ab,ti OR metronomes:ab,ti)) AND (2014:py OR 2015:py OR 2016:py OR 2017:py OR 2018:py OR 2019:py OR 2020:py)) NOT 'melody valve') NOT song:au

(/('resuscitation'/exp OR 'cardiopulmonary resuscitation'/exp OR 'cardio pulmonary resuscitation'/exp OR 'cardiopulmonary resuscitation':ab,ti OR 'cardio pulmonary resuscitation':ab,ti OR cpr:ab,ti OR 'bystander cpr':ab,ti OR 'chest compression':ab,ti OR 'cardiac compression':ab,ti OR 'chest wall compression':ab,ti OR 'thoracic compression':ab,ti OR 'cardiac wall compression':ab,ti OR 'thoracic wall compression':ab,ti OR 'hands-only resuscitation':ab,ti OR 'hands only resuscitation':ab,ti OR 'compression-only cpr':ab,ti OR

\#5 'compression only cpr':ab,ti OR 'heart massage':ab,ti OR 'cardiac massage':ab,ti OR 'thoracic massage':ab,ti OR 'heart arrest/therapy' OR 'cardiac arrest/therapy' OR 'thoracic arrest/therapy') AND ('music'/exp OR music:ab,ti OR song:ab,ti OR songs:ab,ti OR 'singing'/exp OR singing:ab,ti OR humming:ab,ti OR tune:ab,ti OR tunes:ab,ti OR 'melody'/exp OR melody:ab,ti OR melodies:ab,ti OR 'metronome'/exp OR metronome:ab,ti OR metronomes:ab,ti)) AND (2014:py OR 2015:py OR 2016:py OR 2017:py OR 2018:py OR 2019:py OR 2020:py)) NOT 'melody valve'

(('resuscitation'/exp OR 'cardiopulmonary resuscitation'/exp OR 'cardio pulmonary resuscitation'/exp OR 'cardiopulmonary resuscitation':ab,ti OR 'cardio pulmonary resuscitation':ab,ti OR cpr:ab,ti OR 'bystander cpr':ab,ti OR 'chest compression':ab,ti OR 'cardiac compression':ab,ti OR 'chest wall compression':ab,ti OR 'thoracic compression':ab,ti OR 'cardiac wall compression':ab,ti OR 'thoracic wall compression':ab,ti OR 'hands-only resuscitation':ab,ti OR 'hands only resuscitation':ab,ti OR 'compression-only cpr':ab,ti OR

\#4 'compression only cpr':ab,ti OR 'heart massage':ab,ti OR 'cardiac massage':ab,ti OR 'thoracic massage':ab,ti OR 'heart arrest/therapy' OR 'cardiac arrest/therapy' OR 'thoracic arrest/therapy') AND ('music'/exp OR music:ab,ti OR song:ab,ti OR songs:ab,ti OR 'singing'/exp OR singing:ab,ti OR humming:ab,ti OR tune:ab,ti OR tunes:ab,ti OR 'melody'/exp OR melody:ab,ti OR melodies:ab,ti OR 'metronome'/exp OR metronome:ab,ti OR metronomes:ab,ti)) AND (2014:py OR 2015:py OR 2016:py OR 2017:py OR 2018:py OR 2019:py OR 2020:py)

('resuscitation'/exp OR 'cardiopulmonary resuscitation'/exp OR 'cardio pulmonary resuscitation'/exp OR 'cardiopulmonary resuscitation':ab,ti OR 'cardio pulmonary resuscitation':ab,ti OR cpr:ab,ti OR 'bystander cpr':ab,ti OR 'chest compression':ab,ti OR 'cardiac compression':ab,ti OR 'chest wall compression':ab,ti OR 'thoracic compression':ab,ti OR 'cardiac wall compression':ab,ti OR 'thoracic wall compression':ab,ti OR 'hands-only resuscitation':ab,ti OR 'hands only resuscitation':ab,ti OR 'compression-only cpr':ab,ti OR 'compression only cpr':ab,ti OR 'heart massage':ab,ti OR 'cardiac massage':ab,ti OR 'thoracic massage':ab,ti OR 'heart arrest/therapy' OR 'cardiac arrest/therapy' OR 'thoracic arrest/therapy') AND ('music'/exp OR music:ab,ti OR song:ab,ti OR songs:ab,ti OR 'singing'/exp OR singing:ab,ti OR humming:ab,ti OR tune:ab,ti OR tunes:ab,ti OR 'melody'/exp OR melody:ab,ti OR melodies:ab,ti OR 'metronome'/exp OR metronome:ab,ti OR metronomes:ab,ti)

'music'/exp OR music:ab,ti OR song:ab,ti OR songs:ab,ti OR 'singing'/exp OR singing:ab,ti OR humming:ab,ti

\#2 OR tune:ab,ti OR tunes:ab,ti OR 'melody'/exp OR melody:ab,ti OR melodies:ab,ti OR 'metronome'/exp OR metronome:ab,ti OR metronomes:ab,ti

'resuscitation'/exp OR 'cardiopulmonary resuscitation'/exp OR 'cardio pulmonary resuscitation'/exp OR 'cardiopulmonary resuscitation':ab,ti OR 'cardio pulmonary resuscitation':ab,ti OR cpr:ab,ti OR 'bystander cpr':ab,ti OR 'chest compression':ab,ti OR 'cardiac compression':ab,ti OR 'chest wall compression':ab,ti OR

\#1 'thoracic compression':ab,ti OR 'cardiac wall compression':ab,ti OR 'thoracic wall compression':ab,ti OR 'hands-only resuscitation':ab,ti OR 'hands only resuscitation':ab,ti OR 'compression-only cpr':ab,ti OR

'compression only cpr':ab,ti OR 'heart massage':ab,ti OR 'cardiac massage':ab,ti OR 'thoracic massage':ab,ti OR 'heart arrest/therapy' OR 'cardiac arrest/therapy' OR 'thoracic arrest/therapy'

\section{TABLE 4: Embase search queries}




\section{Cureus}

Wednesday, January 22, 2020, 12:20:33 PM

\# Query

Limiters/Expanders

Last Run

Via

Results

Limiters -

Interface -

Published Date:

EBSCOhost

20140101-

Research

20201231

Databases

Expanders - Also

Search

S3 S1 AND S2

search within the

Screen -

Advanced

full text of the

Search

articles Search

modes -

Database -

CINAHL

Boolean/Phrase

with Ful

Text

Interface -

EBSCOhost

Research

( $A B$ (music OR song OR songs $O R$ singing OR hum OR humming OR tune $O R$ tunes OR melody OR melodies OR metronome OR metronomes) OR TI (music OR

S2 song $O R$ songs $O R$ singing $O R$ hum $O R$ humming $O R$ tune $O R$ tunes $O R$ melody OR melodies OR metronome OR metronomes) OR (MH "Music") OR (MH "Singing")) OR "heart massage" OR "cardiac massage" OR "thoracic massage" OR ("heart arrest" AND therapy) OR ("cardiac arrest" AND therapy) OR ("thoracic arrest" AND herapy)) OR TI ("cardiopulmonary resuscitation" OR "cardio pulmonary resuscitation" OR cpr OR "bystander cpr" OR "chest compression" OR "cardiac compression" OR "chest wall compression" OR "thoracic compression" OR "cardiac wall compression" OR "thoracic wall compression" OR "hands-only resuscitation" OR "hands only resuscitation" OR "compression-only cpr" OR "compression only cpr" OR "heart massage" OR "cardiac massage" OR "thoracic massage" OR ("heart arrest" AND therapy) OR ("cardiac arrest" AND therapy) OR ("thoracic arrest" AND therapy)) OR (MH "Resuscitation, Cardiopulmonary") OR (MH "Bystander CPR") OR (MH "Heart Massage") OR (MH "Heart Arrest/TH"))
Expanders - Also search within the full text of the articles Search modes -

Boolean/Phrase

Databases

Search

Screen -

Advanced

Search

Database -

CINAHL

with Full

Text

Interface -

EBSCOhost

Research

Expanders - Also

Databases

Search

Screen -

Advanced

Search

modes -

Database -

CINAHL

with Full

Tex

TABLE 5: CINAHL search queries

ERIC Database

Date Searched: January 22, 2020

("Cardiopulmonary Resuscitation" OR CPR) AND (music OR song OR sing OR metronome OR hum OR tune OR melody)

1 Result - Not relevant because it was outside of the specified date range. 


\section{Cureus}

\# Query

S3 S1 AND S2

(DE "MUSIC" OR DE "MUSIC in education" OR DE "SONGS" OR DE "MELODY" OR DE "MUSICAL composition" OR AB (music OR song OR songs OR singing OR hum OR humming OR tune OR tunes OR melody OR melodies OR

metronome OR metronomes) OR TI (music OR song OR songs OR singing OR hum OR humming OR tune OR tunes OR melody OR melodies OR metronome OR metronomes))
Limiters/Expanders

Via

Results

Interface -

EBSCOhost

Research

Limiters - Published Databases

Date: 20140101-

20201231

Search

Screen -

Advanced

Search

Database -

Psychology

and

Behavioral

Sciences

Collection

Interface -

EBSCOhost

Research

Databases

Expanders - Also

Search

search within the Screen -

full text of the Advanced

articles Search

Search

6,960

modes -

Boolean/Phrase

Database -

Psychology

and

Behavioral

Sciences

Collection

Interface -

EBSCOhost

Research

Databases

Expanders - Also

Search

Screen -

Advanced

Search

full text of the

Database -

Psychology

and

Behavioral

Sciences

Collection

ands only resuscitation" OR "compression-only cpr" OR "compression only cpr" OR "heart massage" OR "cardiac massage" OR "thoracic massage" OR ("heart arrest" AND therapy) OR ("cardiac arrest" AND therapy) OR ("thoracic arrest" AND therapy)))

\section{TABLE 6: Psychology and Behavioral Sciences Collection Database}

Searched Wednesday, January 22, 2020 12:09:28 PM 


\section{Cureus}

\# Query

S3 S1 AND S2

S2

music OR musical OR singing OR song OR songs OR prompt* OR metronome*

CPR OR cardiopulmonary

S1 resuscitation OR cardiorespiratory

resuscitation OR chest compressions OR cardiac arrest
Limiters/Expanders

Limiters - Year of Publication: 20142020 Expanders - Apply equivalent subjects Search modes -

Boolean/Phrase

Expanders - Apply equivalent subjects Search modes -

Boolean/Phrase

Expanders - Apply equivalent subjects Search modes -

Boolean/Phrase
Last Run Via

Results

Interface - EBSCOhost Research

Databases Search Screen -

Advanced Search Database - APA

0

PsycArticles

Interface - EBSCOhost Research

Databases Search Screen -

Advanced Search Database - APA

PsycArticles

Interface - EBSCOhost Research

Databases Search Screen -

Advanced Search Database - APA

PsycArticles

\section{TABLE 7: PsycARTICLES Search Queries}




\section{Cureus}

\# Query

S5 s3 NOT s4

S4 AU song

(DE "CPR (First aid)" OR DE "CPR education" OR (cpr or cardiopulmonary

S3 resuscitation or cardiorespiratory resuscitation or chest compressions or cardiac arrest)) AND (S1 AND S2)

(DE "CPR (First aid)" OR DE "CPR education") OR (cpr or cardiopulmonary

S2 resuscitation or cardiorespiratory resuscitation or chest compressions or cardiac arrest)

(music OR song OR songs OR musical)

S1 OR (DE "MELODY" OR DE "MUSIC in education" OR DE "MUSIC psychology" OR DE "SONGS")
Limiters/Expanders

Limiters - Scholarly (Peer

Reviewed) Journals; Published

Date: 20140101-20181231

Expanders - Apply equivalent subjects Search modes -

Boolean/Phrase

Expanders - Apply equivalent subjects Search modes Boolean/Phrase

Expanders - Apply equivalent subjects Search modes Boolean/Phrase

Expanders - Apply equivalent subjects Search modes Boolean/Phrase

Expanders - Apply equivalent subjects Search modes Boolean/Phrase
Last Run Via

Results

Interface - EBSCOhost Research

Databases Search Screen -

Advanced Search Database - Health

Source: Nursing/Academic

Edition;Health Source - Consumer

Edition

Interface - EBSCOhost Research

Databases Search Screen -

Advanced Search Database - Health

Source: Nursing/Academic

Edition;Health Source - Consumer

Edition

Interface - EBSCOhost Research

Databases Search Screen -

Advanced Search Database - Health

Source: Nursing/Academic

Edition;Health Source - Consumer

Edition

Interface - EBSCOhost Research

Databases Search Screen -

Advanced Search Database - Health

Source: Nursing/Academic

Edition;Health Source - Consumer

Edition

Interface - EBSCOhost Research

Databases Search Screen -

Advanced Search Database - Health

Source: Nursing/Academic

Edition; Health Source - Consumer

Edition

TABLE 8: Health Source: Nursing/Academic Edition/Health Source: Consumer Edition Search Queries

Searched Wednesday, January 22, 2020, 2:04:54 PM

The Networked Digital Library of Theses and Dissertations (NDLTD)

Date Searched: January 22, 2020

description: ("cardiopulmonary resuscitation" OR CPR OR "chest compression" OR "heart massage") AND description: (music OR song OR songs OR singing OR hum OR humming OR tunes OR melody OR melodies OR metronome OR metronomes)

Filters: Publication year 2014-2020

1 result

Appendix B: GRADE Evidence Profile of Dichotomous Outcomes of Compression Rates Within Expected Range and Mean Compression Rate 


\section{Cureus}

\begin{tabular}{|c|c|c|c|c|c|c|c|c|c|c|c|c|}
\hline \multicolumn{7}{|c|}{ Certainty assessment } & \multicolumn{2}{|c|}{ No. of patients } & \multicolumn{2}{|l|}{ Effect } & \multirow[b]{2}{*}{ Certainty } & \multirow[b]{2}{*}{ Importance } \\
\hline $\begin{array}{l}\text { No. of } \\
\text { studies }\end{array}$ & $\begin{array}{l}\text { Study } \\
\text { design }\end{array}$ & $\begin{array}{l}\text { Risk } \\
\text { of } \\
\text { bias }\end{array}$ & Inconsistency & Indirectness & Imprecision & $\begin{array}{l}\text { Other } \\
\text { considerations }\end{array}$ & Song & $\begin{array}{l}\text { No } \\
\text { Song }\end{array}$ & $\begin{array}{l}\text { Relative } \\
(95 \% \mathrm{Cl})\end{array}$ & Absolute $(95 \% \mathrm{Cl})$ & & \\
\hline \multicolumn{13}{|c|}{ Dichotomous } \\
\hline 7 & $\begin{array}{l}\text { randomized } \\
\text { trials }\end{array}$ & $\begin{array}{l}\text { very } \\
\text { serious }{ }^{a}\end{array}$ & serious $^{b}$ & not serious & not serious & none & $\begin{array}{l}360 / 467 \\
(77.1 \%)\end{array}$ & $\begin{array}{l}232 / 443 \\
(52.4 \%)\end{array}$ & $\begin{array}{l}\text { OR } 3.47 \\
\text { (2.00 to } 6.03)\end{array}$ & $\begin{array}{l}269 \text { more per } 1,000 \text { (from } \\
164 \text { more to } 345 \text { more) }\end{array}$ & $\begin{array}{l}\text { ФОOО } \\
\text { VERY LOW }\end{array}$ & CRITICAL \\
\hline \multicolumn{13}{|c|}{ Dichotomous - Day 0} \\
\hline 5 & $\begin{array}{l}\text { randomized } \\
\text { trials }\end{array}$ & $\begin{array}{l}\text { very } \\
\text { serious }{ }^{a}\end{array}$ & serious $^{b}$ & not serious & not serious & none & $\begin{array}{l}138 / 186 \\
(74.2 \%)\end{array}$ & $\begin{array}{l}102 / 174 \\
(58.6 \%)\end{array}$ & $\begin{array}{l}\text { OR } 2.60 \\
\text { (0.97 to } 6.97)\end{array}$ & $\begin{array}{l}200 \text { more per } 1,000 \text { (from } \\
7 \text { fewer to } 322 \text { more) }\end{array}$ & $\begin{array}{l}\text { ФОOО } \\
\text { VERY LOW }\end{array}$ & CRITICAL \\
\hline \multicolumn{13}{|c|}{ Dichotomous - Day 1-29 } \\
\hline 3 & $\begin{array}{l}\text { randomised } \\
\text { trials }\end{array}$ & $\begin{array}{l}\text { very } \\
\text { serious }{ }^{a}\end{array}$ & serious $^{b}$ & not serious & not serious & none & $\begin{array}{l}67 / 83 \\
(80.7 \%)\end{array}$ & $\begin{array}{l}48 / 85 \\
(56.5 \%)\end{array}$ & $\begin{array}{l}\text { OR } 3.02 \\
\text { (0.81 to } \\
11.28 \text { ) }\end{array}$ & $\begin{array}{l}232 \text { more per } 1,000 \text { (from } \\
52 \text { fewer to } 371 \text { more) }\end{array}$ & $\begin{array}{l}\text { ๑OOО } \\
\text { VERY LOW }\end{array}$ & CRITICAL \\
\hline \multicolumn{13}{|c|}{ Dichotomous - Days > 30} \\
\hline 5 & $\begin{array}{l}\text { randomised } \\
\text { trials }\end{array}$ & $\begin{array}{l}\text { very } \\
\text { serious }^{a}\end{array}$ & serious $^{\mathrm{b}}$ & not serious & not serious & none & $\begin{array}{l}155 / 198 \\
(78.3 \%)\end{array}$ & $\begin{array}{l}82 / 184 \\
(44.6 \%)\end{array}$ & $\begin{array}{l}\text { OR } 4.92 \\
\text { (2.22 to } \\
10.94)\end{array}$ & $\begin{array}{l}353 \text { more per 1,000 (from } \\
195 \text { more to } 452 \text { more) }\end{array}$ & $\begin{array}{l}\text { ๑OОО } \\
\text { VERY LOW }\end{array}$ & CRITICAL \\
\hline
\end{tabular}

TABLE 9: GRADE evidence profile of dichotomous outcomes of compression rates within expected range and mean compression rate

aNo blinding. Convenience populations; ${ }^{\text {breporting of outcomes }}$

Appendix C: GRADE Evidence Profile of Mean Compression Depth 


\section{Cureus}

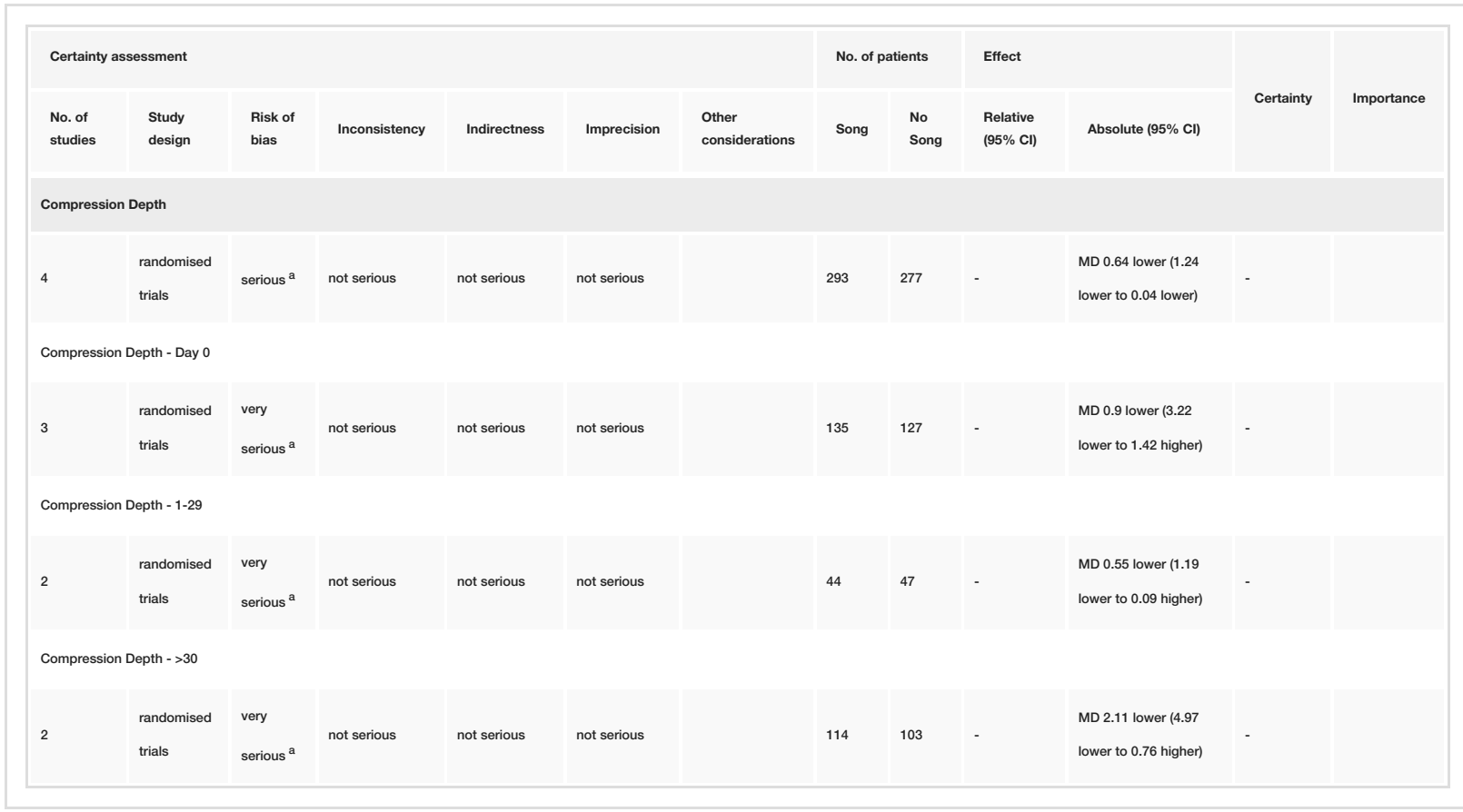

\section{TABLE 10: GRADE evidence profile of mean compression depth}

Cl: Confidence interval; OR: Odds ratio; MD: Mean difference

aNo blinding. Convenience populations.

\section{Additional Information \\ Disclosures}

Conflicts of interest: In compliance with the ICMJE uniform disclosure form, all authors declare the following: Payment/services info: All authors have declared that no financial support was received from any organization for the submitted work. Financial relationships: All authors have declared that they have no financial relationships at present or within the previous three years with any organizations that might have an interest in the submitted work. Other relationships: All authors have declared that there are no other relationships or activities that could appear to have influenced the submitted work.

\section{Acknowledgements}

The authors thank the American Red Cross' Scientific Advisory Council, under the leadership of Dr. David Markenson and Dr. Nici Singletary, for their support and peer review of this work and specifically the Education Sub-council for supporting this work. And, thanks to the Disaster Research Methods class, Spring 2021, at the University of Akron for their contributions to the final editing of the text.

\section{References}

1. Miller B, Pellegrino JL: Measuring intent to aid of lay responders: survey development and validation . Health Educ Behav. 2018, 45:730-4. 10.1177/1090198117749257

2. Snobelen PJ, Pellegrino JL, Nevils GS, Dainty KN: Lay responder post arrest support model: methodology \& conceptual design. BMJ Open. 2018, 8:A10.2-11. 10.1136/bmjopen-2018-EMS.27

3. Snobelen PJ, Pellegrino JL, Nevils GS, Dainty KN: Lay responder post-arrest support model - Methodology \& conceptual model. Emergency Cardiovascular Care Update Conference. 2017, 8:ECCU2017. 10.13140/RG.2.2.17365.12001

4. Pellegrino JL, Oliver E, Orkin A, Marentette D, Snobelen PJ: A call for revolution in first aid education . Int J First Aid Educ. 2017, 1:6061280. 10.21038/ijfa.2017.0001

5. Logan JV, MacDonald D: Empowering first aiders through innovative instructor resources. Int J First Aid Educ. 2018, 2:28.

6. Rea S, Wood F: Minor burn injuries in adults presenting to the regional burns unit in Western Australia: a prospective descriptive study. Burns. 2005, 31:1035-40. 10.1016/j.burns.2005.06.004

7. Uber A, Sadler RC, Chassee T, Reynolds JC: Does non-targeted community CPR training increase bystander CPR frequency?. Prehosp Emerg Care. 2018, 22:753-61. 10.1080/10903127.2018.1459978

8. Pierick TA, Van Waning N, Patel SS, Atkins DL: Self-instructional CPR training for parents of high risk infants. Resuscitation. 2012, 83:1140-4. 10.1016/j.resuscitation.2012.02.007

9. Valeriano A, Van Heer S, de Champlain F, Brooks SC: Crowdsourcing to save lives: a scoping review of 
bystander alert technologies for out-of-hospital cardiac arrest. Resuscitation. 2021, 158:94-121. 10.0.3.248/j.resuscitation.2020.10.035

10. Kurz MC, Bobrow BJ, Buckingham J, et al.: Telecommunicator cardiopulmonary resuscitation: a policy statement from the American Heart Association. Circulation. 2020, 141:e686-700.

10.1161/CIR.0000000000000744

11. Olasveengen TM, Mancini ME, Perkins GD, et al.: Adult basic life support: 2020 international consensus on cardiopulmonary resuscitation and emergency cardiovascular care science with treatment recommendations. Circulation. 2020, 142:S41-9. 10.1161/CIR.0000000000000892

12. Panchal AR, Bartos JA, Cabañas JG, et al.: Part 3: adult basic and advanced life support: 2020 American Heart Association guidelines for cardiopulmonary resuscitation and emergency cardiovascular care. Circulation. 2020, 142:S366-468. 10.1161/CIR.0000000000000916

13. Gibb B, Gibb R, Gibb M: Stayin’ Alive. 1977. https://en.wikipedia.org/wiki/Stayin\%27_Alive.

14. Abella BS, Edelson DP, Kim S, et al.: CPR quality improvement during in-hospital cardiac arrest using a realtime audiovisual feedback system. Resuscitation. 2007, 73:54-61. 10.1016/j.resuscitation.2006.10.027

15. Beckers SK, Skorning MH, Fries M, et al.: CPREzy improves performance of external chest compressions in simulated cardiac arrest. Resuscitation. 2007, 72:100-7. 10.1016/j.resuscitation.2006.05.020

16. Berg RA, Sanders AB, Milander M, Tellez D, Liu P, Beyda D: Efficacy of audio-prompted rate guidance in improving resuscitator performance of cardiopulmonary resuscitation on children. Acad Emerg Med Off J Soc Acad Emerg Med. 1994, 1:35-40.

17. Handley AJ, Handley SAJ: Improving CPR performance using an audible feedback system suitable for incorporation into an automated external defibrillator. Resuscitation. 2003, 57:57-62.

18. Kern KB, Sanders AB, Raife J, Milander MM, Otto CW, Ewy GA: A study of chest compression rates during cardiopulmonary resuscitation in humans. The importance of rate-directed chest compressions. Arch Intern Med. 1992, 152:145-9. 10.1001/archinte.1992.00400130153020

19. Kern KB, Stickney RE, Gallison L, Smith RE: Metronome improves compression and ventilation rates during CPR on a manikin in a randomized trial. Resuscitation. 2010, 81:206-10. 10.1016/j.resuscitation.2009.10.015

20. Merchant RM, Abella BS, Abotsi EJ, et al.: Cell phone cardiopulmonary resuscitation: audio instructions when needed by lay rescuers: a randomized, controlled trial. Ann Emerg Med. 2010, 55:538-543.e1. 10.1016/j.annemergmed.2010.01.020

21. Milander MM, Hiscok PS, Sanders AB, Kern KB, Berg RA, Ewy GA: Chest compression and ventilation rates during cardiopulmonary resuscitation: the effects of audible tone guidance. Acad Emerg Med Off J Soc Acad Emerg Med. 1995, 2:708-13.

22. Wik L, Thowsen J, Steen PA: An automated voice advisory manikin system for training in basic life support without an instructor. A novel approach to CPR training. Resuscitation. 2001, 50:167-72. 10.1016/s03009572(01)00331-8

23. Mancini ME, Soar J, Bhanji F, et al.: Part 12: Education, implementation, and teams: 2010 international consensus on cardiopulmonary resuscitation and emergency cardiovascular care science with treatment recommendations. Circulation. 2010, 122:S539-81. 10.1161/CIRCULATIONAHA.110.971143

24. Travers AH, Perkins GD, Berg RA, et al.: Part 3: adult basic life support and automated external defibrillation. Circulation. 2015, 132:S51-83. 10.1161/CIR.0000000000000272

25. Ouzzani M, Hammady H, Fedorowicz Z, Elmagarmid A: Rayyan-a web and mobile app for systematic reviews. Syst Rev. 2016, 5:210. 10.1186/s13643-016-0384-4

26. Roach JA, Langdon ME, DeFalco R, George CJ: Using music to maintain the correct rhythm during CPR. Nurs Times. 2014, 110:12-5.

27. Roehr CC, Schmölzer GM, Thio M, Dawson JA, Dold SK, Schmalisch G, Davis PG: How ABBA may help improve neonatal resuscitation training: auditory prompts to enable coordination of manual inflations and chest compressions. J Paediatr Child Health. 2014, 50:444-8. 10.1111/jpc.12507

28. Hafner JW, Jou AC, Wang H, Bleess BB, Tham SK: Death before disco: the effectiveness of a musical metronome in layperson cardiopulmonary resuscitation training. J Emerg Med. 2015, 48:43-52. 10.1016/j.jemermed.2014.07.048

29. Hong CK, Hwang SY, Lee KY, Kim YS, Ha YR, Park SO: Metronome vs. popular song: a comparison of longterm retention of chest compression skills after layperson training for cardiopulmonary resuscitation. Hong Kong J Emer Med. 2016, 23:145-52. 10.1177/102490791602300303

30. Leung SFT: The effectiveness of integrating prompt device to basic life support (BLS) training on improving skill mastery of trainee: a systematic review and pilot study. The Chinese University of Hong Kong, Hong Kong; 2016.

31. Tastan S, Ayhan H, Unver V, et al.: The effects of music on the cardiac resuscitation education of nursing students. Int Emerg Nurs. 2017, 31:30-5. 10.1016/j.ienj.2016.06.007

32. Kim KW, Kim JH, Choe WJ, et al.: Effectiveness of 100 beats per minute music on cardiopulmonary resuscitation compression rate education: a manikin study. Hong Kong J Emerg Med. 2017, 24:12. 10.1177/102490791702400102

33. Kneba EJ, Humm KR: The use of mental metronomes during simulated cardiopulmonary resuscitation training. J Vet Emerg Crit Care (San Antonio). 2020, 30:92-6. 10.1111/vec.12915

34. Tricco AC, Lillie E, Zarin W, et al.: PRISMA extension for scoping reviews (PRISMA-ScR): Checklist and explanation. Ann Intern Med. 2018, 169:467-73. 10.7326/M18-0850

35. Andersson B, Ulvaeus, B, Anderson S: SOS. 1975.

36. McMaster University: GRADEpro Guideline Development Tool [Software] . (2020). Accessed: January 28, 2021: https://gradepro.org/.

37. The Nordic Cochrane Centre, The Cochrane Collaboration: Review Manager (RevMan) [Computer program] . (2014). Accessed: January 28, 2021: https://training.cochrane.org/online-learning/core-software-cochranereviews/revman/revman-5-download.

38. Tranchant P, Vuvan, DT, Peretz I: Keeping the beat: a large sample study of bouncing and clapping to music . PLoS ONE. 2016, 11:1-19. 10.0.5.91/journal.pone.0160178 